\title{
LONG-TERM CLINICAL AND HEMODYNAMIC EVALUATION OF PORCINE VALVED CONDUITS IMPLANTED FROM THE RIGHT VENTRICLE TO THE PULMONARY ARTERY
}

Gérard Champsaur, MD

Jacques Robin, MDa

Alain Curtil, MD

François Tronc, $\mathrm{MD}^{\mathrm{a}}$

Catherine Vedrinne, $\mathrm{MD}^{\mathrm{c}}$

François Sassolas, $\mathrm{MD}^{\mathrm{b}}$

André Bozio, $\mathrm{MD}^{\mathrm{b}}$

Jean Ninet, $\mathrm{MD}^{\mathrm{a}}$
Objective: This retrospective study was initiated to evaluate the long-term results of valved prosthetic conduits implanted in the right ventricular outflow tract in patients with complex ventricular-pulmonary discontinuity. Methods: A cohort of 103 patients out of 127 (24 early deaths, 19\%) operated on between 1973 and 1996 with porcine valved conduits was available for evaluation, with a follow-up ranging from 1 to 21.6 years (mean follow-up $8.4 \pm 6$ years). A total of 74 hemodynamic studies were performed after the operation, 50 patients having undergone at least 1 cardiac catheterization during the follow-up period. Results: There were 16 late deaths, and the actuarial survivals, including early mortality, were $\mathbf{7 2 . 9 \%} \pm \mathbf{4 \%}$ at 5 years, $63.1 \% \pm 5 \%$ at 10 years, and $58.2 \% \pm 5 \%$ at 15 years, at which time 20 patients were still available for review and exposed to the risk of dying. The mean peak systolic gradient across the right ventricular outflow tract was plotted as a function of time, showing a gradual increase and a significant step-up after the eighth year, from $43 \pm 36$ to 69 $\pm 19 \mathrm{~mm} \mathrm{Hg}(P<.005)$. Reoperation was required for progressive conduit obstruction between 1.1 and 17.7 years after implantation (mean $7.4 \pm 4.8$ years) in 25 patients $(24 \%, 70 \%$ CL $15 \%-33 \%)$, with generally very few symptoms, or for residual ventricular septal defect in 3 patients. Freedom from reoperation was $79.5 \% \pm 5 \%$ at 10 years and $65.8 \% \pm 7 \%$ at 15 years. Conclusions: Porcine conduits may represent a valuable alternative to biologic substitutes with similar long-term results. Given the few symptoms, progressive conduit stenosis after the eighth postoperative year imposes a yearly noninvasive patient evaluation during the follow-up. (J Thorac Cardiovasc Surg 1998;116:793-804)
$\mathrm{T}$ e concept of bypassing a completely obstructed pulmonary outflow tract, first designed experimentally by Hurwitt $^{1}$ in 1948, was applied clinically in 1964 by Rastelli and associates $^{2}$ in a patient with tetralogy of Fallot, pulmonary atresia, and coronary-pulmonary artery fistula, with the use of an autologous pericardial tubular graft. Aortic homografts, first implanted in a similar situ-

From the Departments of Cardiovascular Surgery, ${ }^{a}$ Pediatric Cardiology, ${ }^{\mathrm{b}}$ and Anesthesia and Postoperative Care, ${ }^{\mathrm{c}}$ Hôpital Cardiologique Louis Pradel, and Claude Bernard University, Lyon, France.

Read at the Seventy-eighth Annual Meeting of The American Association for Thoracic Surgery, Boston, Mass, May 3-6, 1998.

Received for publication May 8, 1998; revisions requested June 17, 1998; revisions received July 13, 1998; accepted for publication July 13, 1998.

Address for reprints: G. Champsaur, MD, Cardiovascular Surgery, Hôpital Cardiologique, 59 Boulevard Pinel, 69003, Lyon, France.

Copyright $\odot 1998$ by Mosby, Inc.

0022-5223/98 $\$ 5.00+0 \quad \mathbf{1 2 / 6 / 9 3 0 8 8}$ ation by Ross and Somerville ${ }^{3}$ in 1966, were also used for the correction of truncus arteriosus in $1968^{4}$ and to repair complex forms of D-transposition of the great vessels, in which case the procedure became known as the "Rastelli" operation. ${ }^{5}$ Because this first generation of generally irradiated homografts became rapidly calcified and obstructive $^{6}$ and their collection became increasingly difficult, Dacron conduits containing porcine aortic valves were ultimately introduced clinically in 1971 by Bowman, Hancock, and Malm. ${ }^{7}$ Numerous reports have since demonstrated that such substitutes, although convenient to use and easily available, are vulnerable to secondary obstruction depending on several factors such as the initial diagnosis, age at implantation, original diameter of the conduit, and other technique-related issues. ${ }^{6,8}$ More recent developments in the storage of homografts, such as cryopreservation, led to the hope for longer-term durability, particularly in children. However, processes of cryopreservation, preparation, and thawing of homografts have evolved with time and may differ from center to cen- 

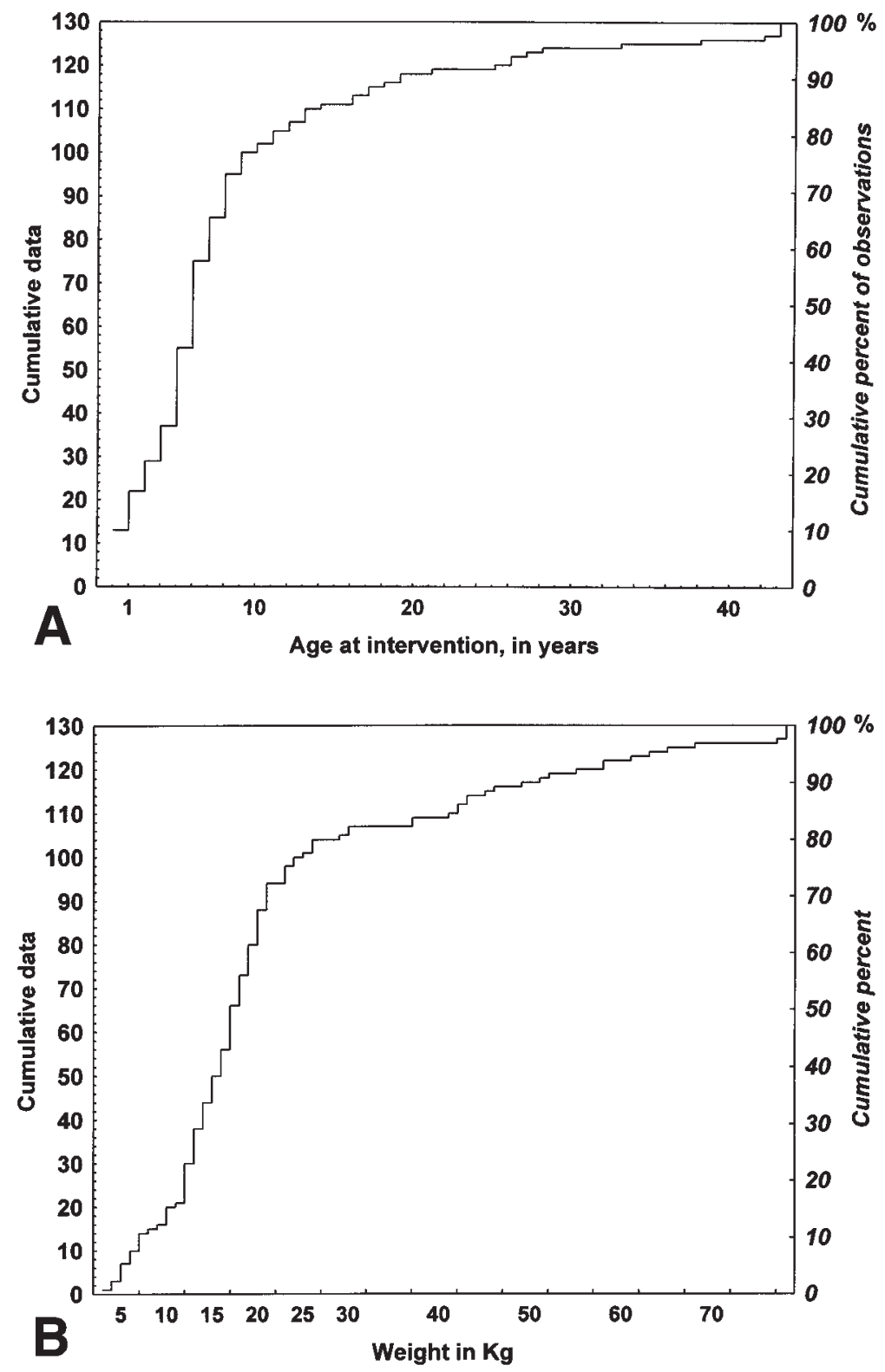

Fig 1. Cumulative distribution plots of age (A) and weight (B) at operation in 127 patients.

ter. In addition, some series show a disappointing longterm outcome of homografts implanted in the pulmonary circulation. ${ }^{9,10}$ Other reports have questioned the use of homograft substitutes in the pediatric population. ${ }^{11}$ However, whatever the conduit, most patients having progressive right ventricular outflow tract (RVOT) obstruction will remain free of symptoms for a long time. ${ }^{6,12,13}$

This study was initiated to evaluate retrospectively the long-term results of porcine valved conduits implanted as a new RVOT in patients with severe congenital ventricular-pulmonary discontinuity.

\section{Patients and methods}

Demographics. A cohort of 127 consecutive patients operated on between July 1973 and December 31, 1996, for complex congenital pulmonary ventricle-pulmonary artery discontinuity with implantation of a porcine valved conduit was available for retrospective analysis.

The ages of the patients ranged from 20 days to 43 years (mean $5 \pm 3.5$ years), with 21 patients $(16.1 \%, 70 \%$ CL $8 \%$ $24.1 \%$ ) being younger than 2 years and 72 patients $(55.4 \%$, $70 \%$ CL $49.5 \%-61.2 \%$ ) younger than 6 years of age, as shown in the distribution depicted in Fig 1. Their weights ranged from 2.3 to $76 \mathrm{~kg}$ (mean $20.4 \pm 14.8 \mathrm{~kg}$ ), 20 patients (15.4\%, 
Volume 116, Number 5

Table I. Initial diagnosis in 127 patients receiving a porcine valved conduit, and summary of early and late results

\begin{tabular}{lccccc}
\hline & \multicolumn{2}{c}{ Patients } & & & \\
\cline { 2 - 4 } Diagnosis & No. & $\%$ & Early deaths & Late deaths & Reoperation in 103 survivors \\
\hline TOF-PA & 42 & 33 & 8 & 5 & 7 \\
D-TGV & 25 & 20 & 3 & 2 & 8 \\
Truncus & 21 & 17 & 9 & 6 & 5 \\
DORV & 20 & 16 & 3 & 3 & 5 \\
CTGV & 18 & 14 & 0 & 0 & 0 \\
DOLV & 1 & & 24 & 16 & 0 \\
Total & 127 & & 0 & 25 \\
\hline
\end{tabular}

TOF-PA, Tetralogy of Fallot and pulmonary atresia; $d-T G V$, D-transposition of the great vessels; $C T G V$, corrected transposition of the great vessels; $D O R V$, doubleoutlet right ventricle. DOLV, double-outlet left ventricle; VSD, ventricular septal defect; $P S$, pulmonary stenosis.

$70 \%$ CL $7.3 \%-23.4 \%$ ) weighing less than $10 \mathrm{~kg}$ and 88 patients $(67.7 \%, 70 \%$ CL $62.8 \%-72.7 \%)$ less than $20 \mathrm{~kg}$ at the time of the operation, as shown in Fig 1. Overall clinical characteristics of patients are displayed in Table I, with stratification according to the diagnosis, and a number of preimplantation palliative procedures are detailed in Table II. Associated lesions were represented by a right aortic arch in 14 cases, an anomalous left anterior descending coronary artery originating from the right in 13 cases, dextrocardia in 10 cases, situs inversus totalis in 5 cases, an absent pulmonary valve complex in 1 case, and a single right pulmonary artery in 1 case.

Surgical technique. Operations were conducted in a standard manner with intermittent aortic crossclamping at $25^{\circ} \mathrm{C}$ until 1976 and cold crystalloid cardioplegia thereafter (mean bypass time $138.6 \pm 35.5$ minutes and mean aortic crossclamp time $75.2 \pm 23$ minutes). For conduit implantation, the distal anastomosis was performed first, and generally before aortic crossclamping. The valved segment of the conduit was placed as close to the distal pulmonary artery anastomosis as possible, and the position of the conduit relative to the ascending aorta was dictated by the size and the position of the vessel. A Carpentier-Edwards conduit (Baxter Healthcare Corp, Edwards Division, Santa Ana, Calif) was implanted in 46 patients and a Hancock conduit (Medtronic, Inc, Minneapolis, Minn) was implanted in 81 patients, without random assignment. Concomitant aortic valve replacement was performed in 5 patients with truncus arteriosus and truncal valve stenosis or insufficiency. The distribution of conduit sizes is displayed in Fig 2, the commonest sizes being $20 \mathrm{~mm}$ (38.5\% of the cases, $70 \%$ CL $31 \%-45 \%)$ and $22 \mathrm{~mm}$ (22\% of the cases, $70 \% \mathrm{CL}$ $14 \%-29 \%$ ). There was a positive correlation between the sizes of the conduits and both the age and the weight of the patients (Fig 3). Since 1986, patients have been subjected to an anticoagulation protocol, including heparin for the first postoperative week and aspirin, $100 \mathrm{mg} /$ day, thereafter.

Follow-up. The postoperative evaluation consisted of regular clinical follow-up at the outpatient clinic, along with serial echocardiography, magnetic resonance imaging, hemodynamic assessment, or a combination of these studies, performed when any anomaly was thought to be related to an increase in right ventricular-pulmonary artery pressure gra-
Table II. Pre-implantation palliative procedures

\begin{tabular}{lr}
\hline Procedures & No. \\
\hline Blalock-Taussig shunt & 40 \\
Pulmonary artery banding & 15 \\
Waterston shunt & 9 \\
Blalock-Hanlon & 6 \\
Potts anastomosis & 2 \\
Aortopulmonary window & 2 \\
Total & 74 \\
\hline
\end{tabular}

dient. Thus 74 postoperative serial hemodynamic studies were available at some time during the follow-up period, with a second cardiac catheterization in 24 patients. In 6 patients, a balloon angioplasty either of the valvular proximal anastomotic site or of the distal pulmonary artery stenosis was attempted, a repeat procedure being performed in 3 instances. When needed, a second operation for replacement of an obstructed conduit was conducted on the basis of lateral chest xray findings. Peripheral cannulation and hypothermia were used only when there was an obvious narrow relation between the conduit and the posterior table of the sternum. ${ }^{6}$ Early mortality was defined as death occurring within 30 days of the operation. For the statistical analysis, data were entered into a computerized database and analyzed with a statistical package (STATISTICA, StatSoft, Inc, Tulsa, Okla). Descriptive summary of data included mean \pm standard deviation for continuous variables and proportions for categoric variables, with levels of significance determined with Spearman correlation coefficients. Between-group differences in continuous variables were assessed with $t$ tests and analysis of variance. The cumulative survival estimates of patients and survivorship free of reoperation were made by the Kaplan-Meier method with comparison of 2 or more survival functions by means of the log-rank test. The 5 variables considered for univariable analysis were age and weight at operation, year of operation, initial diagnosis, and conduit diameter. A multivariable analysis, with the use of the Cox proportional hazards model, was performed to identify independent risk factors for both patient mortality and reoperation on variables found to be approaching statistical significance at univariable analysis, with a $P$ value $<.05$. 


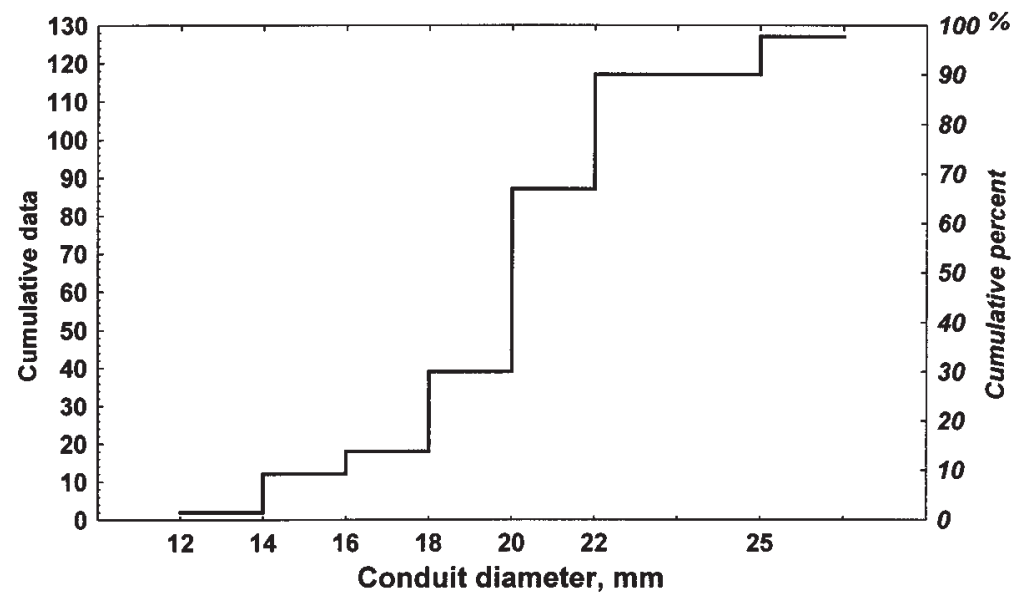

Fig 2. Cumulative distribution plot of conduit sizes in millimeters.

Table III. Causes of late deaths in 103 operative survivors

\begin{tabular}{lllr}
\hline Patient No. & Diagnosis & \multicolumn{1}{c}{ Cause } & Postop time (mo) \\
\hline 1 & Truncus & At conduit replacement, previous PA banding, severe left PA stenosis & 70 \\
2 & Truncus & RV dysfunction, persistent PAH, truncal valve regurgitation (grade 3) & 71 \\
3 & Truncus & At conduit re-replacement for conduit infection, hemorrhage & 72 \\
4 & Truncus & Accidental (traumatic spleen rupture) & 138 \\
5 & Truncus & RV dysfunction, persistent PAH, truncal valve regurgitation (grade 2) & 36 \\
6 & Truncus & RV dysfunction, persistent PAH, truncal valve regurgitation (grade 2) & 3 \\
7 & TOF-PA & RV dysfunction, single PA & 211 \\
8 & TOF-PA & Acute respiratory distress, absent PA valve & 6 \\
9 & TOF-PA & RV dysfunction, severe left PA stenosis, unilateral right PAH & 6 \\
10 & TOF-PA & Diminutive PAs, localized PAH in 2 lobar territories & 96 \\
11 & TOF-PA & Diminutive PAs, systemic collaterals, repeat hemoptysis & 11 \\
12 & DORV & At conduit re-replacement, hemorrhage & 45 \\
13 & DORV & Persistent LV dysfunction & 11 \\
14 & DORV & Documented ventricular fibrillation & 10 \\
15 & D-TGV & Septic shock and circulatory collapse & 3 \\
16 & D-TGV & Acute conduit obstruction & 116
\end{tabular}

$R V$, Right ventricle; $P A$, pulmonary artery; $P A H$, pulmonary artery hypertension.

\section{Results}

Early results. Overall early mortality was $19 \%$ (24 patients), the incidence of early deaths being higher in patients operated on before $1986\left(26 \%\right.$ vs $13 \%, \chi^{2}, P=$ .02 ), weighing less than $10 \mathrm{~kg}$, or having a conduit smaller than $18 \mathrm{~mm}\left(\chi^{2}, P=.008\right)$. Inasmuch as the focus of the study is primarily on long-term results, early results will not be further detailed.

Patient survival. There were 16 late deaths, which occurred from 3 months to 17.5 years after the initial operation (mean $4.6 \pm 4$ years, median 3.4 years). The causes of late deaths are listed in Table III, stratified by initial diagnosis. In the 103 operative survivors, followup ranged from 1 to 21.6 years, with a mean follow-up of $8.4 \pm 6$ years (median 7 years, 70\% CL 7.7-9 years).
The follow-up was more than 10 years in 33 patients, $(32 \%, 70 \%$ CL 24\%-40\%) and more than 15 years in 28 patients (27\%, 70\% CL 19\%-35\%). Complete followup was obtained in all patients. At univariable analysis, risk factors for late mortality were year of operation before 1986, age less than 3 years, and initial diagnosis of truncus arteriosus (analysis of variance, $P=.02$ ).

Actuarial survival, including early mortality, was $72.9 \% \pm 4 \%$ at 5 years, $63.1 \% \pm 5 \%$ at 10 years, and $58.2 \% \pm 5 \%$ at 15 years, at which point 20 patients were still exposed (Fig. 4). At multivariable analysis, the only independent risk factors for late mortality were age younger than 3 years $(P=.03)$ and initial diagnosis of truncus arteriosus $(P=.01)$, as displayed in Fig. 5 .

Hemodynamic data. Sites of conduit obstruction 

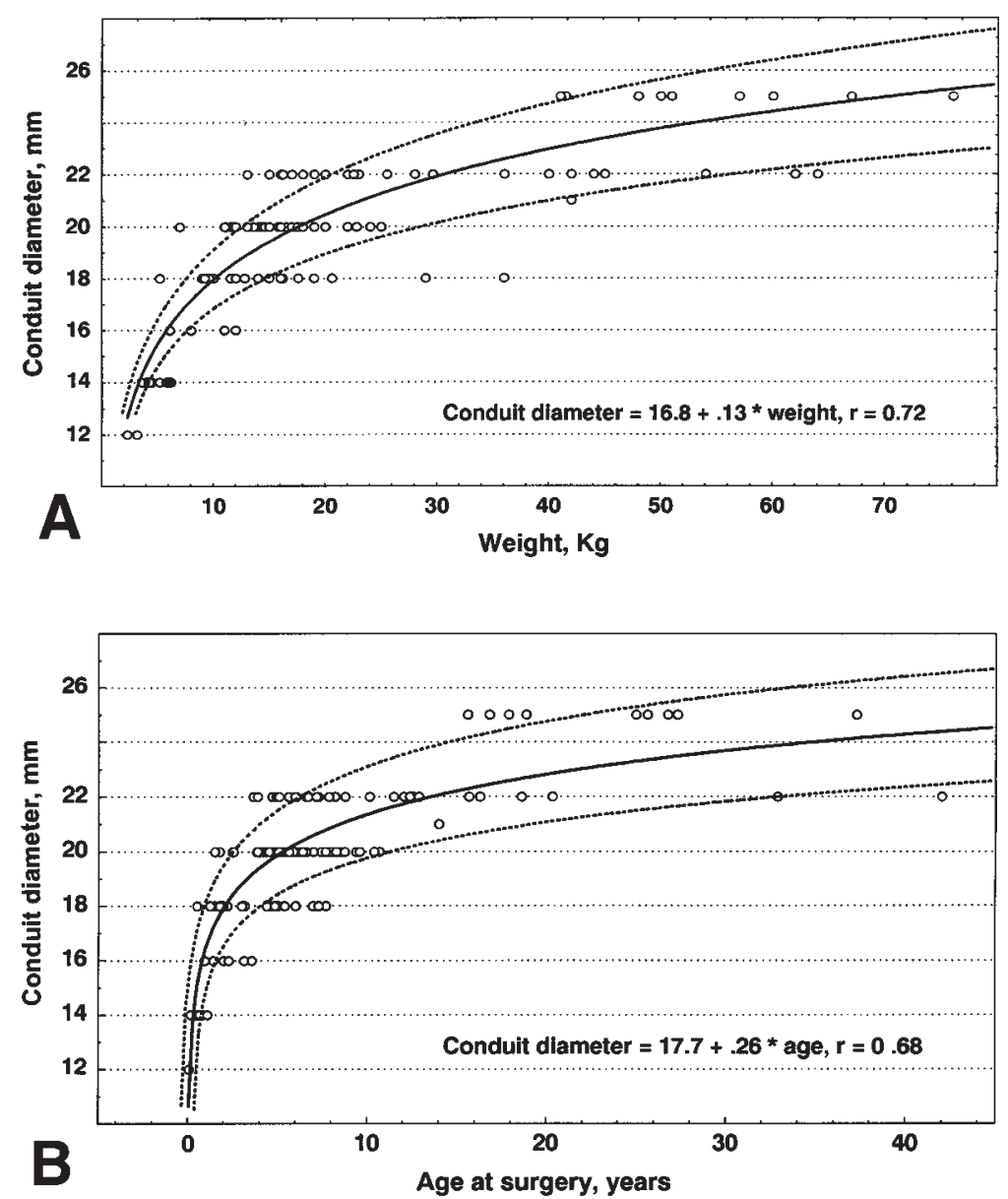

Fig 3. Scattergram and nomogram of regression equation displaying relations between conduit diameter and weight (A) and age (B) at operation in 127 patients (confidence bands for the $70 \%$ confidence intervals).

were predominantly at the valve level in 10 cases, behind the sternum as a result of sternal compression in 5 cases, at the proximal anastomosis in 4 cases, and at the distal site in 3 cases. A significant residual left-toright shunt $(>2)$ was found in 3 cases. Postoperative hemodynamic data (mean peak systolic gradient across the RVOT and mean peak systolic right ventricular pressure) were plotted as a function of time. For the purpose of analysis, time between the first operation and the hemodynamic study was arbitrarily divided into 4 intervals of 4 years. RVOT gradient increased gradually over time, with a significant step-up after the eighth postoperative year from $43 \pm 36$ to $69 \pm 19 \mathrm{~mm} \mathrm{Hg}(P$ $=.04)$. Meanwhile, the right ventricular pressure, although generally following the same evolution, became significantly elevated $(P=.01)$ earlier during the follow-up, that is, as early as the fourth postoperative year (Fig 6).
Reoperation. Reoperation was required in 25 cases (24\%, 70\% CL 15\%-33\%) for progressive conduit obstruction confirmed between 1.1 and 17.7 years after implantation (mean $7.4 \pm 4.8$ years) in patients with generally very few symptoms, or for a residual left-toright shunt at the ventricular level in 3 patients. Time interval before reoperation was related only to weight at the operation, being $6.8 \pm 4$ years in children weighing less than $10 \mathrm{~kg}$ versus $14.6 \pm 0.3$ years in patients weighing more than $10 \mathrm{~kg}$ (analysis of variance, $P=$ .02 ). Whatever the predominant site of obstruction leading to reoperation, intimal peel was present to some extent in all explanted conduits. Obstructed conduits were replaced by either a new valved substitute (7 cases), a nonvalved substitute (5 cases), or, more recently, a plain Dacron roofing patch ${ }^{14}$ (10 cases), with 3 of the late deaths occurring early after surgery for conduit replacement (1 case) or re-replacement (2 cases). Thus 


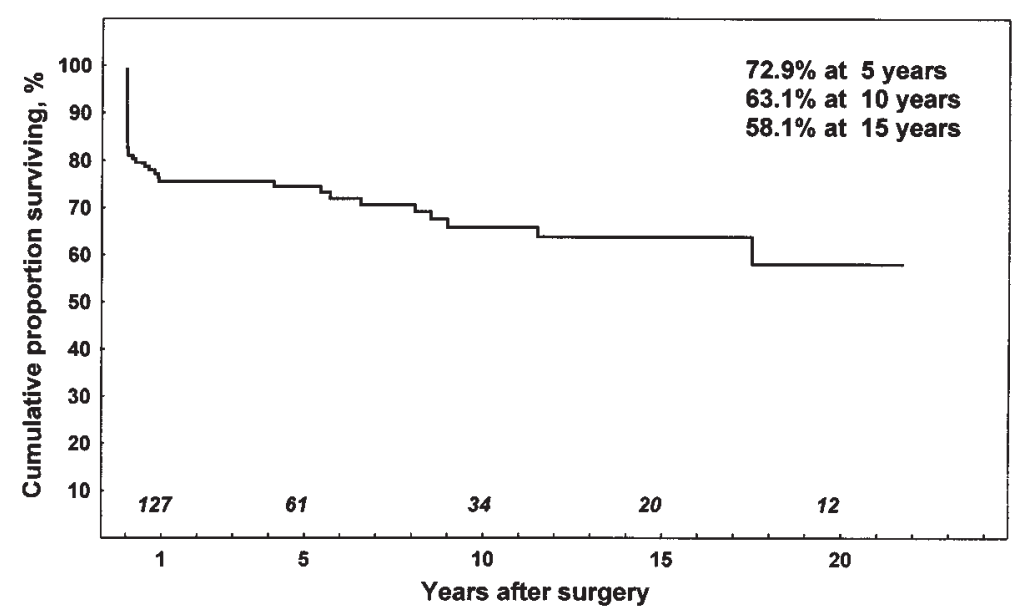

Fig 4. Global actuarial survival, including early mortality. The number of patients exposed at a given time interval is given in italics.

rates of freedom from reoperation among patients surviving the initial perioperative period were $93.6 \% \pm 2 \%$ at 5 years, $79.5 \% \pm 5 \%$ at 10 years, and $65.8 \% \pm 7 \%$ at 15 years (Fig 7). Actuarial freedom from reoperation was not significantly different in patients operated on before or after 1986 (log-rank test, $P=.96$ ). Finally, at multivariable analysis, initial diagnosis of corrected transposition of the great vessels, with no patients yet requiring reoperation, was the only significant predictor of freedom from reoperation in this patient population $(P$ $=.01)$. It is noteworthy that 5 female patients who had a conduit replaced (4 nonvalved and 1 valved) were able to have normal pregnancies. One of them, with tetralogy of Fallot and pulmonary atresia, gave birth to a baby who has since undergone a complete correction of a regular form of tetralogy of Fallot (anecdotal report).

Finally, no significant difference was detected in the performance of the two types of conduits used (Carpentier-Edwards or Hancock) in terms of patient survival, hemodynamics, or reoperation.

\section{Discussion}

The long-term outcome of a variety of substitutes to treat anatomic ventricular-pulmonary artery discontinuity form the basis of a large and often controversial body of reference papers in the surgical literature, ${ }^{6,10,12,14,15}$ a familiar indicator that the quest for the optimal substitute still goes on. Moreover, inclusion of different types of substitutes in most articles makes separate analysis of data from specific groups of patients more difficult. In addition, most studies lack extensive hemodynamic evaluation of porcine composite conduits. In the present series, the significant increase in the mean peak systolic right ventricular-pulmonary artery gradient after the eighth postoperative year is unusually late. This may be due in part to the rather large sizes of conduits (20 and $22 \mathrm{~mm}$ in more than half of the population), whereas the age distribution is similar to that of most series, except for large series of neonates and infants with truncus arteriosus. ${ }^{16-21}$ Meanwhile, why a significant change in the mean peak systolic right ventricular pressure seems to occur more often early during the follow-up than the change in gradient remains questionable. A possible explanation might be found in the presence of a greater number of patients with elevated pulmonary artery pressure during the earliest hemodynamic evaluations that were performed for early conduit dysfunction or residual defects, or both.

The long-term outcome in our series compares favorably with that of others, with freedom from reoperation for conduit replacement ranging from $94 \%$ at 5 years in the broadest series ever reported on the follow-up of such RVOT substitutes ${ }^{6,14}$ to $37 \%$ at 5 years in a series in which more than half of the conduits were less than $18 \mathrm{~mm} .{ }^{15}$ The 5 -year freedom from reoperation was still $60 \%$ at 5 years in the largest reported series of patients with truncus arteriosus, in which $54 \%$ of the 124 Hancock conduits implanted were $12 \mathrm{~mm} \cdot{ }^{21}$ Most patients with truncus in our series were either older (mean age 33 months, range 23 days -8 years) or had a previous banding, as more often performed before the 1980s. This may explain why most early deaths among patients with truncus arteriosus were still due to persistent pulmonary hypertension, particularly at a time when current pharmacologic assistance was not available (eg, prostaglandin, nitric oxide). In addition, the presence of a previous pulmonary artery banding with 

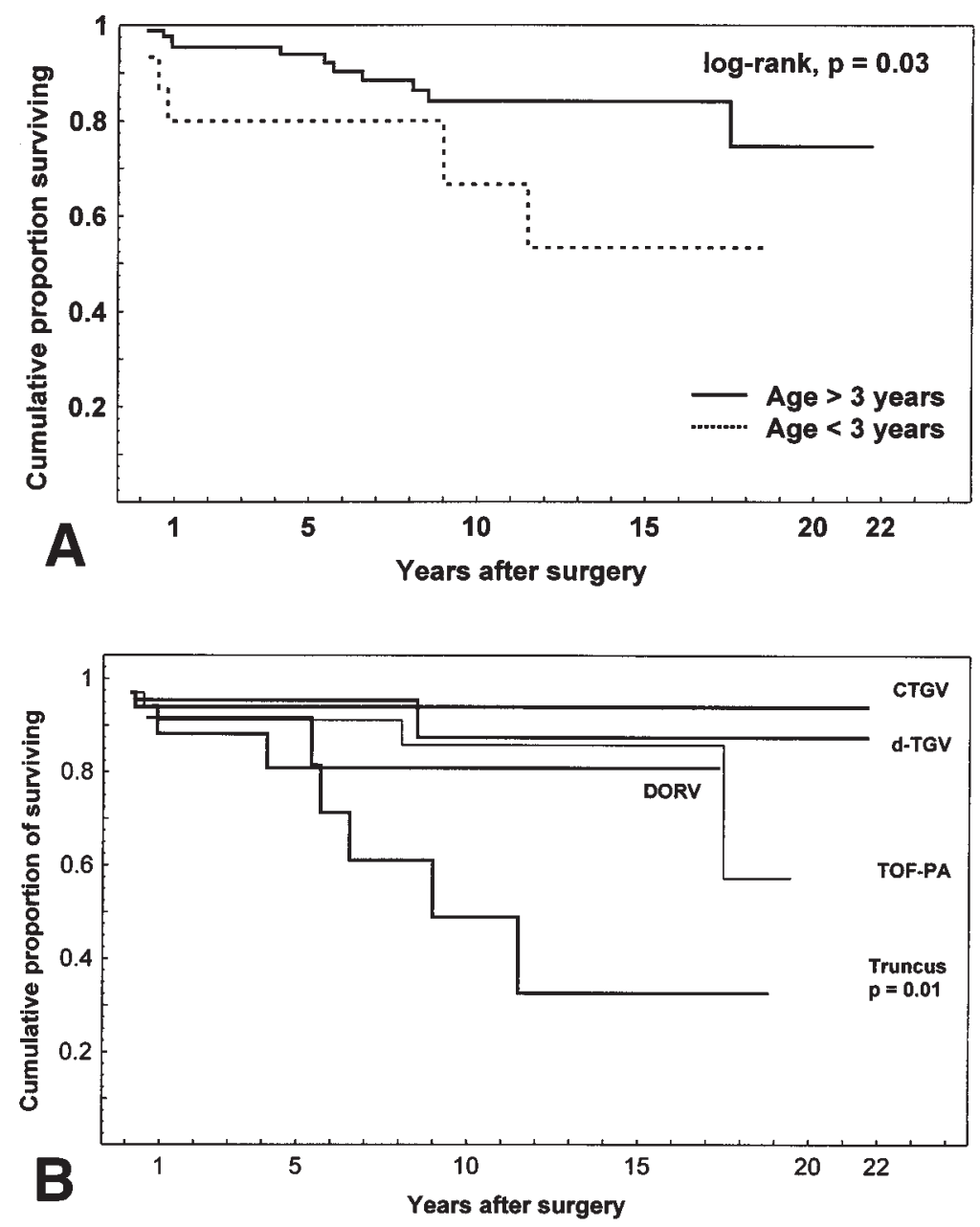

Fig 5. Actuarial survival stratified either by age at operation over or under 3 years (A) or by initial diagnosis (B). Early mortality is excluded in this analysis. $C T G V$, Corrected transposition of the great vessels; $d-T G V$, D-transposition of the great vessels; TOF-PA, tetralogy of Fallot and pulmonary atresia; DORV, double-outlet right ventricle.

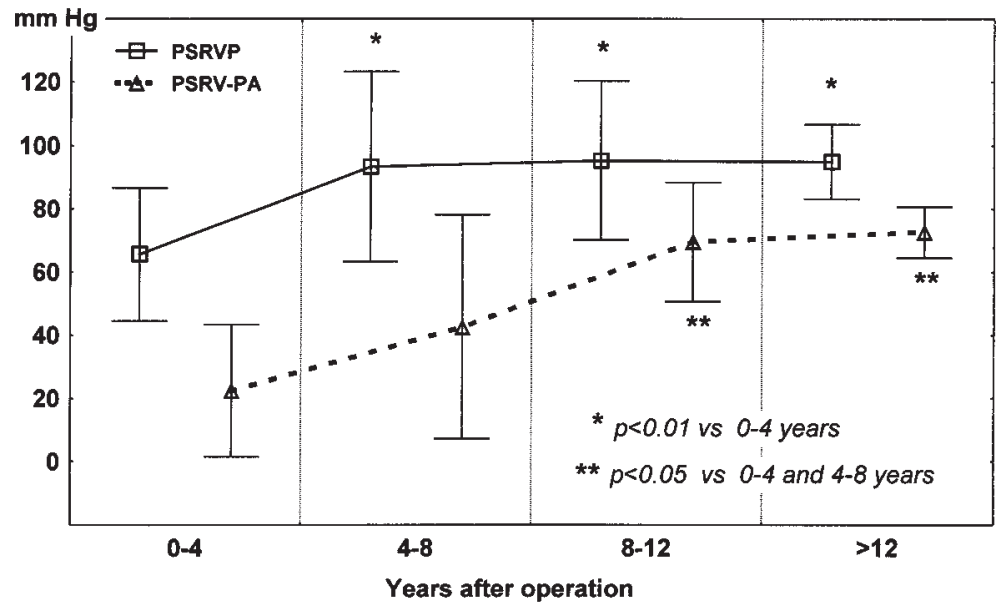

Fig 6. Plot of peak systolic right ventricular-pulmonary artery gradient ( $P S R V-P A)$ and peak systolic right ventricular pressure $(P S R V P)$ at 4 different 4-year intervals during the follow-up. 

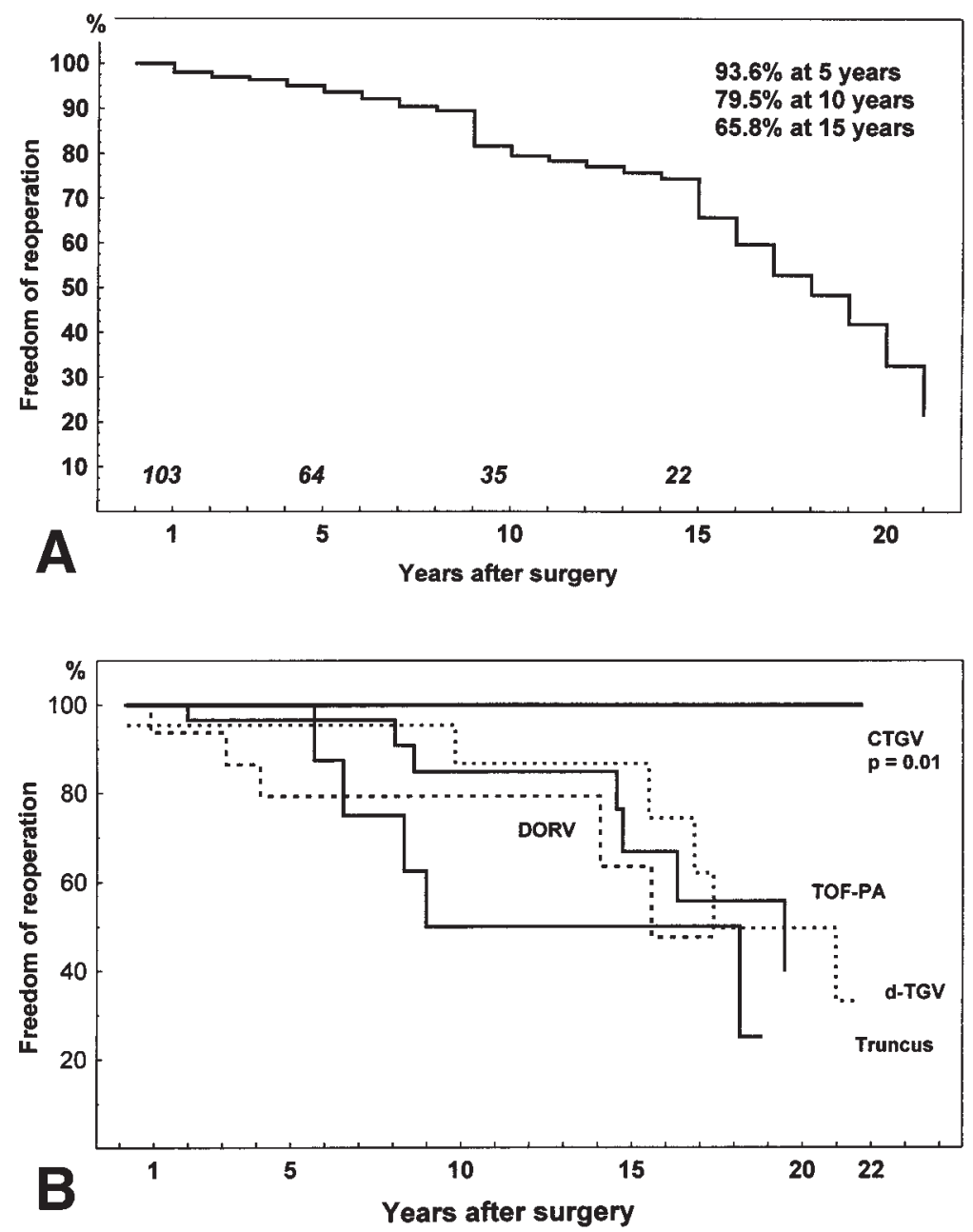

Fig 7. Freedom from reoperation, global (A) or stratified by initial diagnosis (B). CTGV, Corrected transposition of the great vessels; $d-T G V$, D-transposition of the great vessels; TOF-PA, tetralogy of Fallot and pulmonary atresia; DORV, double-outlet right ventricle.

Table IV. Demographics and outcome data collected from published series

\begin{tabular}{|c|c|c|c|c|c|c|c|c|}
\hline $\begin{array}{l}\text { Ref } \\
\text { No. }\end{array}$ & First author & Year & $\begin{array}{l}\text { No. of } \\
\text { patients }\end{array}$ & $\begin{array}{l}\text { No. of porcine } \\
\text { conduits }\end{array}$ & Mean age & $\begin{array}{c}\text { No. of } \\
\text { reoperations }\end{array}$ & $\begin{array}{l}\text { Time before } \\
\text { reoperations }\end{array}$ & $\begin{array}{l}\text { Freedom from } \\
\text { reoperation }\end{array}$ \\
\hline 8 & Bailey & 1977 & 85 & 49 & $10.2 \mathrm{y}$ & 7 & & $70 \%$ at $5 y$ \\
\hline 6 & McGoon & 1982 & 468 & 333 & $9.8 \mathrm{y}$ & 56 & & $94 \%$ at $5 y$ \\
\hline 12 & Jonas & 1985 & 201 & 123 & $9 \mathrm{y}$ & 34 & & $86 \%$ at $5 \mathrm{y}$ \\
\hline 24 & Bull & 1987 & 249 & 135 & $>4 \mathrm{y}$ & 23 & & $68 \%$ at $5 \mathrm{y}$ \\
\hline 20 & Boyce & 1988 & 49 & 49 & $3.5 \mathrm{~m}$ & 28 & $4.5-101 \mathrm{~m}$ & NA \\
\hline 15 & Sano & 1991 & 141 & 126 & $5.9 \mathrm{y}$ & 45 & & $37 \%$ at $5 y$ \\
\hline 17 & Pearl & 1991 & 32 (TA) & 8 & $3.5 \mathrm{~m}$ & 5 & $15-40 \mathrm{~m}$ & NA \\
\hline 10 & Razzouk & 1992 & 457 & 126 & $9 y$ & 93 (overall) & & $89 \%$ at $5 y$ \\
\hline 23 & Albert & 1993 & 163 & 24 & $4.2 \mathrm{y}$ & 6 & & $70 \%$ at $5 y$ \\
\hline 16 & Bove & 1993 & 46 (TA) & 4 & $13 \mathrm{~d}$ & 1 & $52 \mathrm{~m}$ & NA \\
\hline 21 & Reddy & 1995 & 222 (TA) & 124 & $4 \mathrm{~m}$ & 52 & & $60 \%$ at $5 y$ \\
\hline 14 & Danielson & 1995 & 500 & 359 & 9.9 & 67 & & $94 \%$ at $5 \mathrm{y}$ \\
\hline
\end{tabular}

Reference numbers correspond to those in the reference section. $T A$, Truncus arteriosus; $N A$, not available. 
stenosis or kinking of the pulmonary bifurcation inevitably increased the risk of early and late death, as well as that of reoperation.

The issue of timing for conduit replacement is very sensitive. As reported by others, a progressive increase in right ventricular pressure is usually well tolerated, and most patients will have a rather mild complaint in the absence of associated defects. ${ }^{6,13}$ Given the increased risk of severe conduit stenosis or obstruction between the fourth and eighth postoperative years in our series, hemodynamic assessment should be recommended within this time frame. Meanwhile, routine and eventually repeated catheterization is not well accepted in the pediatric population. Less invasive follow-up is therefore mandatory, and a good correlation between echocardiography and hemodynamics has been demonstrated in patients undergoing RVOT reconstruction with homografts. ${ }^{13}$ This should be extrapolated to porcine conduits, although very little data are available on this matter. This is one of the reasons that we have recently relied on magnetic resonance imaging, the latest developments in this less invasive technology allowing an accurate and repeatable evaluation of the conduit anatomy (Fig 8).

Interestingly, the probability of reoperation in this study remains relatively low $(6.4 \%$ at 5 years and $20.5 \%$ at 10 years), particularly since 1986 , and the incidence of late mortality is low as well. Heparin and aspirin therapies, which were introduced that very year, potentially explain a difference which, being found only at univariable analysis, may still be coincidental.

The traditional alternative to porcine conduit is usually the aortic or pulmonary homograft, and less than optimal midterm to long-term results have been achieved with even the latest generation of cryopreserved homografts in the pediatric population..$^{9-11,22-24}$ Thus valve survival was only $46 \% \pm 13 \%$ at 5 years in a series of 178 homografts implanted in the RVOT, with similar performances for aortic or pulmonary homografts. ${ }^{10}$ Conversely, in a large series of 326 patients with a mean age of 11.4 years (aortic) and 14.4 years (pulmonary), freedom from reoperation was similar to that obtained with porcine conduits (94\% at 5 years) when pulmonary homografts were used, but only $70 \%$ with the use of aortic homografts. ${ }^{22}$ In very small conduits, like the ones needed for early correction of truncus arteriosus, homografts may bring the advantages of ease of tailoring and suturing. ${ }^{21}$ However, in some countries, difficulties in collecting small homografts and tight regulations imposed on biologic substitutes almost preclude their regular use. Moreover, in the absence of a truly prospective comparative study, the advantages of homografts over

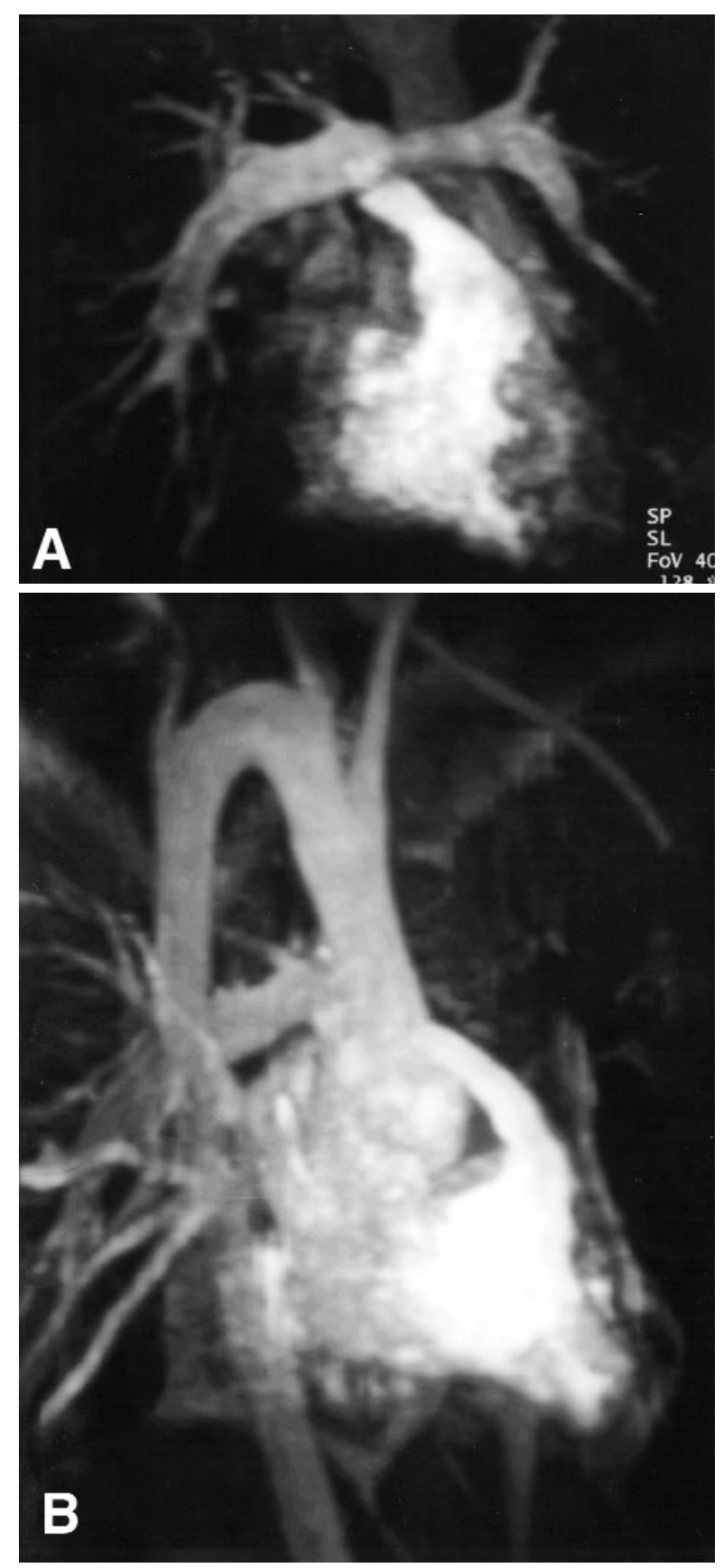

Fig 8. Three-dimensional contrast-enhanced magnetic resonance angiography combining fast 3-dimensional acquisition and the intravenous injection of paramagnetic contrast media demonstrating near-normal patency of the right ventricular-pulmonary artery conduit in a symptom-free patient with D-transposition and a $20-\mathrm{mm}$ conduit implanted 19 years earlier when the child was 17 months old. The peak systolic right ventricular-pulmonary artery gradient was $40 \mathrm{~mm} \mathrm{Hg}$. A, Anteroposterior view, with clear representation of the segmental and subsegmental branches of both pulmonary arteries. B, Lateral view, with the same acquisition a bit later demonstrating the right and left circulations. 
porcine conduits even in very young patients remain controversial. Time exposure is still relatively short in most series, with a mean of 23.4 months ${ }^{19}$ to 44 months. ${ }^{16}$ In most studies, the homograft was an aortic graft that usually necessitated a gusset augmentation by a piece of Dacron fabric on the proximal anastomosis, eventually facilitating the development of later obstruction. ${ }^{17}$

Finally, avoiding the use of any conduit seems to be the ideal solution, as first suggested by Lecompte ${ }^{25}$ and implemented by other groups in patients with truncus arteriosus. ${ }^{26,27}$ However, experiences so far seem limited, with only 1 long-term oral report in the English literature (reference 16, discussion). Other more technical propositions have remained anecdotal in the clinical field, suggesting the use of either autologous pericardium $^{28,29}$ or valveless conduits. ${ }^{30}$

In conclusion, porcine valved conduits used to reconstruct the RVOT show long-term performances comparable with those of other biologic substitutes in large sizes. Inasmuch as conduit obstruction has discrete clinical manifestations, careful noninvasive follow-up is recommended as early as the fourth postoperative year.

We acknowledge D. Revel, MD, Chief of Service, Radiology Department, Hopital Cardiologique, for his expert contribution in magnetic resonance angiography.

\section{REFERENCES}

1. Hurwitt ES. An experimental approach to the problem of increasing the blood supply to the lungs: preliminary observations on the use of plastics. Surg Gynecol Obstet 1948;87:816-16.

2. Rastelli GC, Ongley PA, Davis GD, Kirklin JW. Surgical repair for pulmonary valve atresia with coronary-pulmonary artery fistula: report of a case. Mayo Clin Proc 1965;40:521-7.

3. Ross DN, Somerville J. Correction of pulmonary atresia with a homograft aortic valve. Lancet 1966;2:1446-7.

4. McGoon DC, Rastelli GC, Ongley PA. An operation for the correction of truncus arteriosus. JAMA 1968;205:69-73.

5. Rastelli GC, Wallace RB, Ongley PA. Complete repair of transposition of the great arteries with pulmonary stenosis: a review and report of a case corrected by using a new surgical technique. Circulation 1969;39:83-95.

6. McGoon DC, Danielson GK, Puga FJ, Ritter DG, Mair DD, Ilstrup DM. Late results after extracardiac conduit repair for congenital cardiac defects. Am J Cardiol 1982;49:1741-9.

7. Bowman Jr FO, Hancock WD, Malm JR. A valve-containing Dacron prosthesis: its use in restoring pulmonary artery-right ventricular continuity. Arch Surg 1973;107:724-8.

8. Bailey WW, Kirklin JW, Bargeron LM, Pacifico AD, Kouchoukos NT. Late results with synthetic valved conduits from venous ventricle to pulmonary arteries. Circulation 1977;56(Suppl):II73-9.

9. Cleveland DC, Williams WG, Razzouk AJ, Trusler GA, Rebeyka IM, Duffy L, et al. Failure of cryopreserved homograft valved conduits in the pulmonary circulation. Circulation 1992;86 (Suppl):II150-3.
10. Razzouk AJ, Williams WG, Cleveland DC, Coles JG, Rebeyka IM, Trusler GA, et al. Surgical connections from ventricle to pulmonary artery: comparison of four types of valved implants. Circulation 1992;86(Suppl):II154-8.

11. Clarke DR, Campbell DN, Hayward AR, Bishop DA. Degeneration of aortic valve allografts in young recipients. J Thorac Cardiovasc Surg 1993;105:934-43.

12. Jonas RA, Freed MD, Mayer JE, Castaneda AR. Long term follow-up of patients with synthetic right heart conduits. Circulation 1985;72(Suppl):II77-83.

13. Chan KC, Fyfe DA, McKay CA, Sade RM, Crawford FA. Right ventricular outflow reconstruction with cryopreserved homografts in pediatric patients: intermediate-term follow-up with serial echocardiographic assessment. J Am Coll Cardiol 1994;24: 483-9.

14. Danielson GK, Anderson BJ, Schleck CD, Ilstrup DM. Late results of pulmonary ventricle to pulmonary artery conduits. Semin Thorac Cardiovasc Surg 1995;7:162-7.

15. Sano S, Karl TR, Mee RBB. Extracardiac valved conduits in the pulmonary circuit. Ann Thorac Surg 1991;52:285-90.

16. Bove EL, Lupinetti FM, Pridjian AK, Beekman RH, Callow LB, Snider AR, et al. Results of a policy of primary repair of truncus arteriosus in the neonate. J Thorac Cardiovasc Surg 1993;105: 1057-66.

17. Pearl JM, Laks H, Drinkwater DC, Milgalter E, Charas OA, Giacobetti F, et al. Repair of truncus arteriosus in infancy. Ann Thorac Surg 1991;52:780-6.

18. Heinemann MK, Hanley FL, Fenton KN, Jonas RA, Mayer JE, Castaneda AR. Fate of small homograft conduits after early repair of truncus arteriosus. Ann Thorac Surg 1993;55:1409-12.

19. Hanley FL, Heinemann MK, Jonas RA, Mayer JE, Cook NR, Wessell DL, et al. Repair of truncus arteriosus in the neonate. $\mathrm{J}$ Thorac Cardiovasc Surg 1993;105:1047-56.

20. Boyce SW, Turley K, Yee ES, Verrier ED, Ebert PA. The fate of the $12 \mathrm{~mm}$ porcine valved conduit from the right ventricle to the pulmonary artery. J Thorac Cardiovasc Surg 1988;95:201-7.

21. Reddy VM, Rajasinghe HA, McElhinney DB, Hanley FL. Performance of right ventricle to pulmonary artery conduits after repair of truncus arteriosus: a comparison of Dacron-housed porcine valves and cryopreserved allografts. Semin Thorac Cardiovasc Surg 1995;7:133-8.

22. Bando K, Danielson GK, Schaff HV, Mair DD, Julsrud PR, Puga FJ. Outcome of pulmonary and aortic homografts for right ventricular outflow tract reconstruction. J Thorac Cardiovasc Surg 1995;109:509-18.

23. Albert JD, Bishop DA, Fullerton DA, Campbell DN, Clarke DR. Conduit reconstruction of the right ventricular outflow tract: lessons learned in a twelve-year experience. $\mathbf{J}$ Thorac Cardiovasc Surg 1993;106:228-36.

24. Bull C, Macartney FJ, Horvath P, Almeida R, Merrill W, Douglas $\mathrm{J}$, et al. Evaluation of long-term results of homograft and heterograft valves in extracardiac conduits. J Thorac Cardiovasc Surg 1987;94:12-9.

25. Lecompte Y, Neveux JY, Leca F, Zannini L, Tu TV, Dubois Y, et al. Reconstruction of the pulmonary outflow tract without prosthetic conduit J Thorac Cardiovasc Surg 1982;84:727-33.

26. Barbero-Marcial M, Atik E, Jatene A. A technique for correction of truncus arteriosus types I and II without extracardiac conduits. J Thorac Cardiovasc Surg 1990;99:364-9.

27. Nakae S, Kawada M, Kasahara S, Kuroyama N, Hiraishi S, 
for the repair of truncus arteriosus. Ann Thorac Surg 1996;61:990-2.

28. Rendina EA, Venuta F, De Giacomo T, Vizza DC, Ricci C. Reconstruction of the pulmonary artery by a conduit of autologous pericardium. J Thorac Cardiovasc Surg 1995;110:867-8.

29. Iemura J, Oku H, Otaki M, Kitayama H, Matsumoto T. Reconstruction of right ventricular outflow tract by pedicled pericardial valved conduit. Ann Thorac Surg 1997;64:1849-51.

30. Behrendt DM, Dick M. Truncus repair with a valveless conduit in neonates. J Thorac Cardiovasc Surg 1995;110:1148-50.

\section{Discussion}

Dr Ivan M. Rebeyka (Edmonton, Alberta, Canada). This retrospective analysis of clinical results with the porcine valved conduit from Lyon, France, addresses one of the remaining weak links in surgery for congenital heart diseaseconduit reconstruction of the RVOT. More than 25 years of clinical experience has been accrued with the use of Dacron conduits incorporating a porcine valve to achieve right ventricular-pulmonary artery continuity, but unfortunately the experience with reoperation for conduit obstruction is nearly as long. An emphasis on complete repair in the neonate may compound the problem by increasing the number of infants at risk of simply outgrowing their conduits. The 1988 report from Dr Ebert's group, which looked specifically at the fate of $12 \mathrm{~mm}$ conduits, is particularly noteworthy in demonstrating that only about one third lasted more than 5 years.

The results of this retrospective study indicate that the $94 \%$ rate of freedom from reoperation at 5 years falls to $80 \%$ by 10 years, which highlights the false impression of conduit longevity that short-term follow-up studies might imply. This is further emphasized by the findings of a significant step-up in conduit gradient after the eighth year. However, an $80 \%$ survival at 10 years for porcine valved conduits is longer than virtually all previously reported results with this device. This survival figure also implies that the porcine conduit outlasts the aortic homograft in the pulmonary position and may even outperform the pulmonary homograft. Although primary autologous reconstruction of the RVOT will be less prone to late obstruction, right ventricular failure owing to pulmonary regurgitation would adversely influence the reoperation rate.

This leads me to my first question. Given these superb late results with the porcine valved conduit and assuming an appropriately sized pulmonary homograft was available, what is your conduit of choice within the RVOT in the infant age group and in what situations would you opt for a direct connection between the pulmonary artery and right ventricle?

Second, you implanted a substantial number of both the Hancock and the Carpentier-Edwards conduits. Experience has taught us that subtle differences in valve processing and construction of bioprosthetic valves can influence durability. Can you find any difference in the late results when comparing these 2 types of porcine valved conduits?

Finally, a univariate analysis of your results suggests a lower incidence of reoperation after 1986 when a protocol of long-term low-dose aspirin was initiated. Why do you think platelet-dose aspirin might be effective, considering that previous studies have supported the concept that progressive thickening of the lining peel takes place primarily along the interface between the peel and the conduit rather than the interface between the peel and the lumen?

Dr Champsaur. Thank you, Dr Rebeyka. We are well aware of your participation in some extensive studies coming from the Toronto group on this particular subject. Regarding your first question on our current use of conduits in small infants, we have used homografts for the past 5 years. However, some countries like ours have tight regulations on the use of biologic substitutes. These preclude the use of such small conduits in the infant population. We are no longer allowed to harvest homografts from nonbeating donors, so we are still awaiting an ideal substitute. We have in 3 instances used a downsized adult homograft with good early results, but this is all the hard data I have.

Regarding the comparison between the Hancock and Carpentier-Edwards, these conduits were not assigned randomly. We used whichever type of conduit was available. However, we did an analysis and found no statistically significant difference between the two substitutes.

Regarding long-term use of low-dose aspirin, this prescription was recommended by the cardiologists, but I do not think there is any scientific ground to support its use. Also, the year 1986 was not an independent predictor of a better outcome. Thus I do not think that aspirin plays a role in the long-term outcome.

Dr Stefano Conte (Winksele, Belgium). Considering the wide spectrum of cardiac anomalies in your series, I think that your rather high early mortality $(19 \%)$ has to be considered more in relation with the difficult repair of complex cardiac anomalies than with the implantation of the right ventricular conduit in itself. I would like to focus more on the durability of the porcine conduits, particularly in the group of patients with tetralogy of Fallot.

I recently reviewed our experience with pulmonary valve replacement with cryopreserved homografts in almost 50 patients after previous repair of tetralogy of Fallot or pulmonary stenosis. Both early and late mortalities were very low. At a follow-up ranging from 1 to 8 years, we observed no instances of conduit obstruction or reoperation for pulmonary valve failure, and only 2 patients has mild pulmonary stenosis.

Although we did not have any instances of midterm conduit obstruction, as you did in your series, the mean followup in our series is not long enough yet to allow proper comparison with regard to the durability between homograft and porcine valved conduits.

However, the reoperation rate of $24 \%$ for conduit obstruction, reported in your study, is considerably higher than the reoperation rate recently reported in the literature; for example, the Toronto group recently reported a reoperation rate of $10 \%$, using mainly porcine conduits and having a follow-up comparable with yours. Did you find any specific reason for this difference? 
Finally, what are your criteria for using or not using a new valved conduit in the reoperations? In other words, inasmuch as you did not replace the pulmonary valve in the majority of the reoperations, do you really believe that the issue of pulmonary regurgitation and related progressive right ventricular failure would be less important than pulmonary stenosis in the setting of further reoperations?

Dr Champsaur. We did look carefully into the literature, and we found that our reoperation rate was a little lower than what was previously published. As long as we were dealing with older children, the results were just about the same. The $24 \%$ reoperation rate you refer to is a crude one. The actuarial freedom from reoperation was $93 \%$ at 5 years and $80 \%$ at 10 years, comparable with those of other published series. I think that the great number of large conduits that we used might explain why this rate is a little better in our series.

Regarding the second question, at reoperation we prefer to use a valved conduit if the distal pulmonary artery pressure is not normal or if there is stenosis or a risk of stenosis that is not amenable to surgery on the distal pulmonary artery branches. In those cases, we would choose a valved conduit rather than a nonvalved conduit.

\section{Bound volumes available to subscribers}

Bound volumes of The Journal of Thoracic and Cardiovascular Surgery are available to subscribers (only) for the 1998 issues from the Publisher, at a cost of $\$ 122.00$ for domestic, $\$ 151.94$ for Canadian, and $\$ 142.00$ for international subscribers for Vol 115 (January-June) and Vol 116 (July-December). Shipping charges are included. Each bound volume contains a subject and author index and all advertising is removed. Copies are shipped within 60 days after publication of the last issue of the volume. The binding is durable buckram with the Journal name, volume number, and year stamped in gold on the spine. Payment must accompany all orders. Contact Mosby, Inc, Subscription Services, 11830 Westline Industrial Drive, St Louis, MO 63146-3318, USA; phone 800-453-4351 or 314-453-4351.

Subscriptions must be in force to qualify. Bound volumes are not available in place of a regular Journal subscription. 